
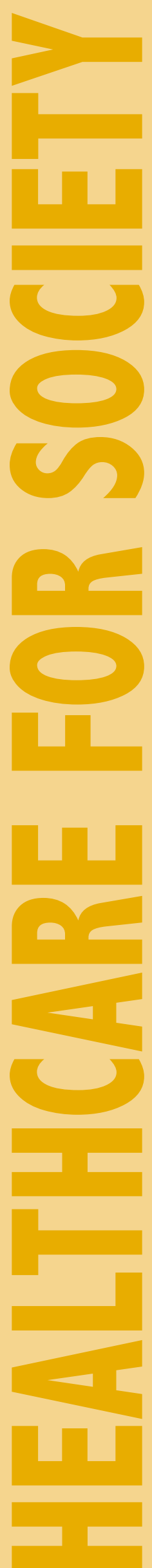

\title{
Advocacy for resuscitation: any CPR is better than no CPR. An interview with Dr Axel Siu
}

by: Venice Li, Hilary Kwok, Joey Chan

Year 6 (MB, ChB), The Chinese University of Hong Kong

https://doi.org/10.12809/hkmj-hc202002

The beeps of the machines that monitor patients and the motions of the team of healthcare providers tending to the patients combine to form the intense and action-packed atmosphere of the accident and emergency department that Dr Axel Siu revels in. As an emergency medicine specialist in Ruttonjee Hospital, Hong Kong, this is where his passion lies-a place where every second matters and every decision can mean life or death. But his passion doesn't stop at the entrance to the accident and emergency ward, it extends through the clinical and administrative work of revising resuscitation guidelines, and beyond, into the public where his involvement in educating the public on out-of-hospital cardiac arrest has had farreaching effects.

\section{Career highlights}

After graduating from The Chinese University of Hong Kong in 1992, Dr Siu spent his time as a junior medical officer at Pamela Youde Nethersole Eastern Hospital and this sparked his passion for emergency medicine. He relished the constant challenge of having to make a diagnosis with few investigations and within a limited time frame. His increasing ability to arrive at a timely diagnosis made his newfound passion incredibly rewarding. The fact that his work made a substantial difference to his patients' condition and recovery made it all the more fulfilling.

When asked about his most memorable patient, Dr Siu avidly recounts the time when a young man came into the accident and emergency department with back pain. Initially it had appeared to be a simple musculoskeletal case, but Dr Siu detected a subtle abnormality and ordered a computed tomography scan. As he suspected, the scan revealed an aortic dissection! Dr Siu reflects that it is events like this that make him grateful for the passion he has developed for emergency medicine, and the ability to make a difference to patients' lives when they first arrive at the hospital.

As the years progressed, Dr Siu not only wholeheartedly fulfilled his clinical duties, but also took up administrative positions in various organisations. In 2008, he became a council member of the Hong Kong College of Emergency Medicine and was elected as President in 2017. During his time in the council, Dr Siu has seen numerous advancements in his specialty, including the development of point-ofcare ultrasound for identifying small pneumothoraxes and other conditions. Dr Siu has also been involved in establishing the concept of advanced life support in Hong Kong, with its extension to Macau. He has even been supporting the development of emergency medicine in Myanmar.

\section{Educating the public}

During his precious free time, Dr Siu is an avid sportsman with a love for running and hiking. He integrated this hobby and his profession by developing the field of Wilderness Medicine in Hong Kong. After attending training sessions in the United States, he took it upon himself to establish workshops in Hong Kong. Initially this was to educate fellow colleagues, but in one mid-term break, Dr Siu extended his efforts to teaching secondary school students by accompanying them on an overseas trip to Mount 
Kinabalu in Malaysia.

Dr Siu's particular passion is for educating the public on the importance and steps of bystander cardiopulmonary resuscitation (CPR). A small incident sparked this enthusiasm when he participated in a $10 \mathrm{~km}$ race at Science Park in 2012. While running, he encountered a young runner who collapsed suddenly and went into cardiac arrest. Instinctively, Dr Siu immediately performed CPR on the man, as if on any other day in the accident and emergency ward. He fondly recounts that the man survived and, to this day, they remain very good friends. Undoubtedly, he is very grateful that Dr Siu was around on that fateful day. This even also had a profound effect on Dr Siu, placing in him a strong urge to educate the public on basic CPR skills to save more lives. "As an emergency medicine doctor," says Dr Siu, "I have seen many cases which patients might have survived if someone could have performed CPR."

Dr Siu points out that a major problem in Hong Kong is that people are afraid to perform CPR and use automatic external defibrillators (AEDs). Bystanders with various degrees of CPR knowledge may choose not to carry out CPR when the time comes, for various reasons. For example, some fear legal consequences if the outcome of the collapsed victim is not favourable. Others assume that formal training is needed in order to operate an AED. Many people are unaware that AEDs are designed to be user-friendly and operated by lay-people, with clear voice prompts and the administration of a shock only if the patient needs one. Dr Siu believes that a 'Good Samaritan's Law' should be implemented in Hong Kong to allay fears of legal action and to encourage people to do CPR when needed by exempting them from litigation. Similar laws have already been implemented in neighbouring regions including mainland China, Taiwan, and Japan. "When saving lives, every second count," urges Dr Siu, "and although the CPR may be substandard, any CPR is better than no CPR. I hope a 'Good Samaritan's Law' can be implemented in Hong Kong to protect those who choose to save lives out of the goodness of their heart."

Dr Siu also actively promotes the importance of CPR and how to carry it out effectively by teaching students in schools and the public in exhibition events. He finds this experience extremely rewarding as he is able to put into action what he encourages others to do. To advocate resuscitation to the public in an interactive way, Dr Siu sometimes needs to put down his white coat. In a video promoting infant CPR, he dressed up as the Tang Priest and sung an arranged version of the theme song 'Only You' from Stephen Chow's 'A Chinese Odyssey Part Two: Cinderella'. In another video, he plays Iron Head in 'Shaolin Soccer' to teach parents to resuscitate their children. He hopes that these creative ideas could spark interest in the public to pursue life-saving CPR knowledge.

\section{Room for improvement}

Dr Siu's passion for promoting CPR to the public follows him wherever he goes. He recounts anecdotes from his travels abroad, such as a trip to Japan when he hiked to the top of Mount Fuji and was pleasantly surprised to discover an AED was placed at the summit. He was equally pleased to find that taxis in Singapore are equipped with AEDs. Such accounts highlight the lengths to which some countries prioritise the importance of bystander CPR and accessibility of AEDs.
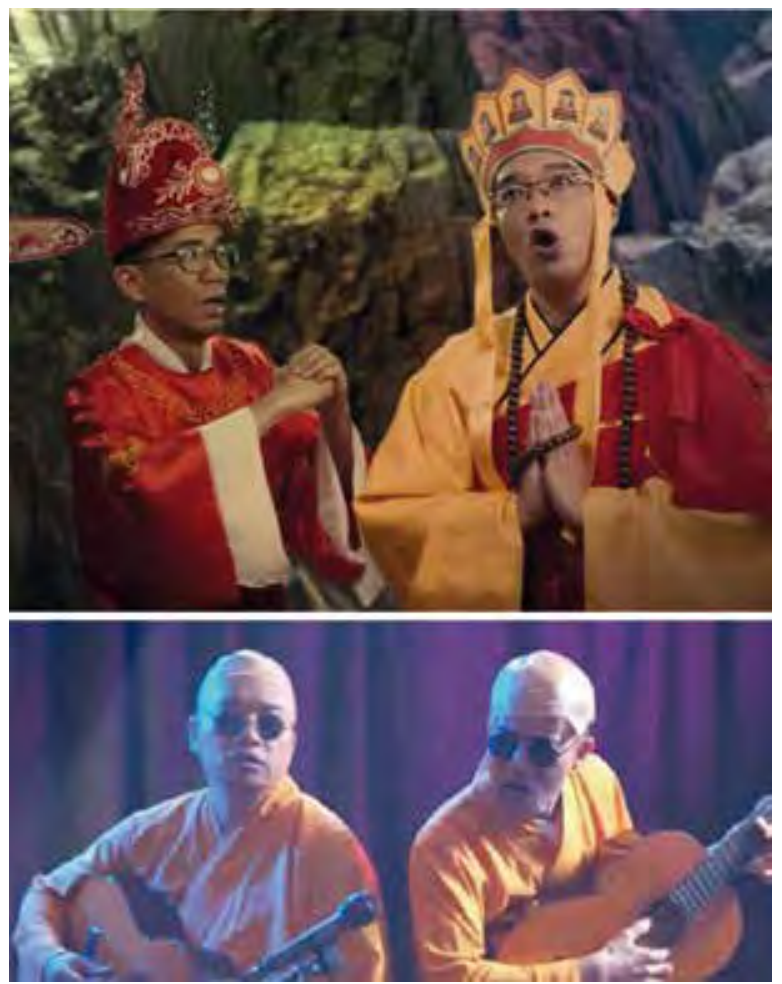

Dr Siu taking part in promotional videos to promote resuscitation to the public

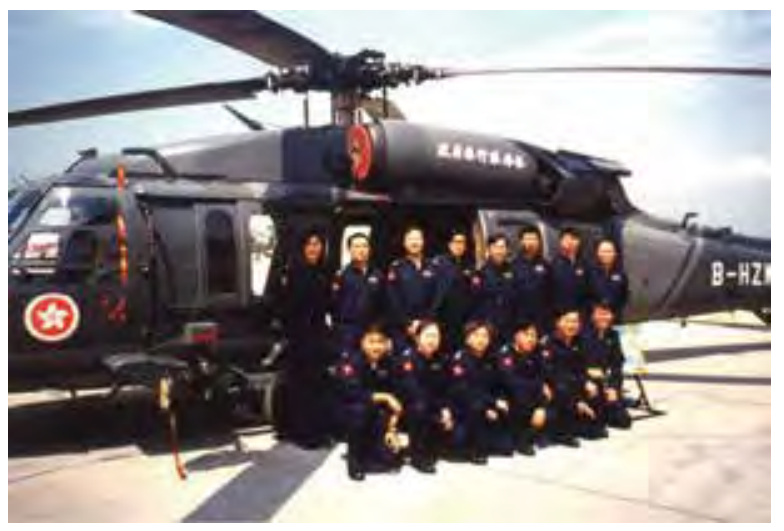

Participation in emergency air medical services 


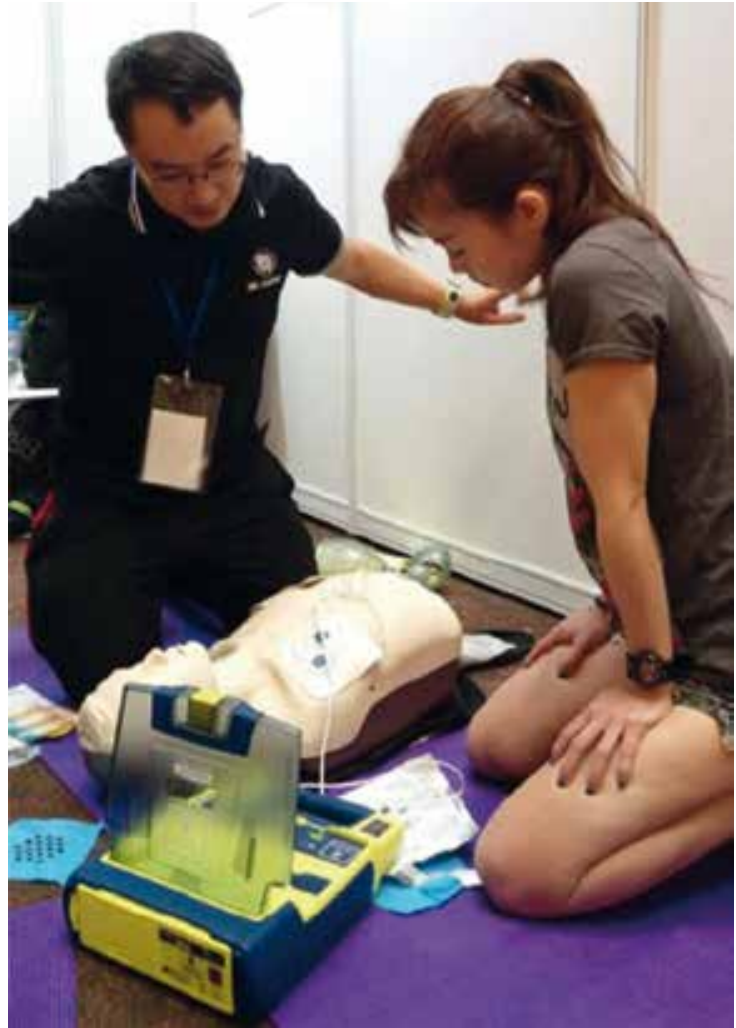

Public education on cardiopulmonary resuscitation and the use of automatic external defibrillators

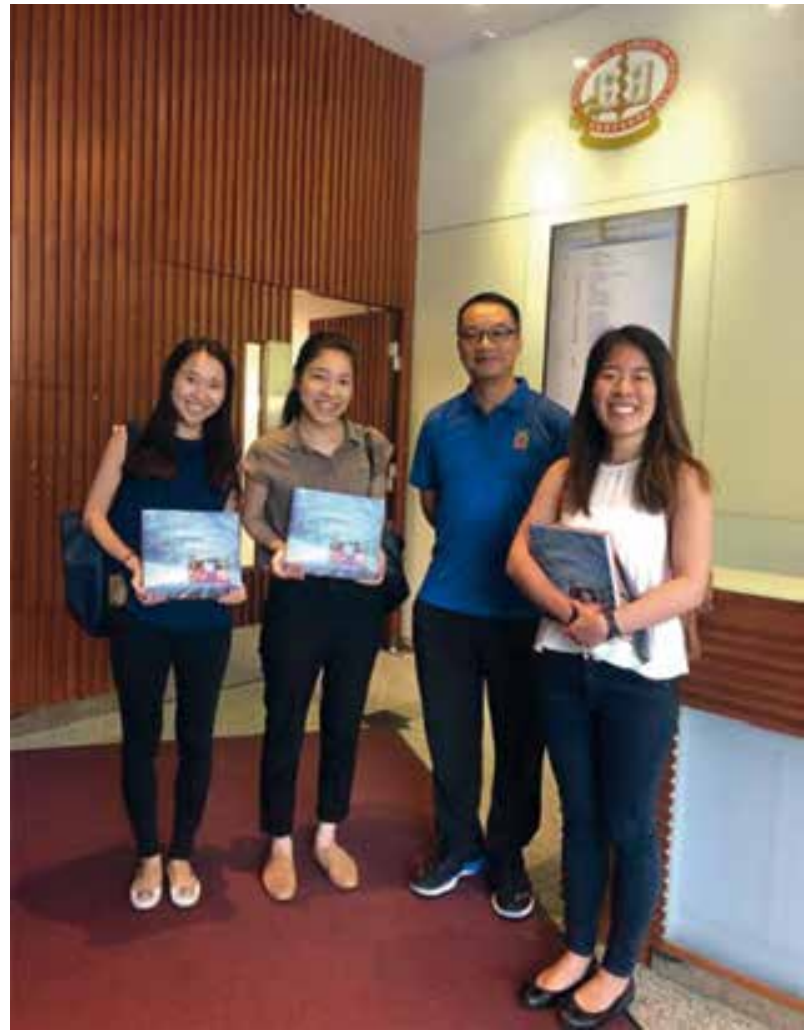

Dr Siu with the journal's student reporters (from left): Venice, Hilary and Joey
"There is still much room for improvement" was Dr Siu's reply when asked about the situation of out-of-hospital cardiac arrests in Hong Kong, based on his research in the subject. ${ }^{1}$ The ageing population in Hong Kong contributes to a low survival rate; however, the lack of bystander CPR knowledge, coupled with the sparse placement of AEDs throughout the city, the lack of confidence in performing CPR, and the fear of legal consequences, has severely hindered the survival rate in Hong Kong.

With the collective efforts of healthcare professionals, the Fire Services Department, and various other organisations, improvements are being made and new ideas are being put forward in Hong Kong. To improve knowledge of CPR among students, teachers, and parents, extra-curricular activities in schools have been initiated. It is hoped that by allowing the public to see the value and importance of doing CPR when the time comes, they can help not only their loved ones, but also people they come across in the community. As Dr Siu said, "By planting seeds, we can harvest interest and save more people." Although Hong Kong has yet to integrate CPR courses as part of the compulsory school curriculum, as is the practice in Japan, we are taking our first step in creating a healthier community.

Dr Siu also advocates implementing an AED registry. ${ }^{1}$ Currently, AEDs can be purchased without official registration. This makes it hard to track the numbers and locations of AEDs in the community. A registry, with formal registration for every AED purchased, including the intended location, would allow all AEDs in Hong Kong can be mapped. Mapping of AEDs is already in place in Singapore and has been further extended through a mobile phone application, myResponder. This application cleverly mobilises volunteers familiar with CPR throughout the community. Whenever a cardiac arrest arises, volunteers within $400 \mathrm{~m}$ are notified. Bystanders can locate an AED and receive face-to-face instruction in how to perform CPR and use an AED before arriving at the scene. Using this example, Dr Siu demonstrates the vast opportunities available in expanding public awareness and education on CPR and AEDs.

With a positive outlook, Dr Siu hopes that public education in bystander CPR will reach all corners of society. His advice to medical professionals is to equip themselves with skills and knowledge first and to "mobilise people around you". To the Hong Kong community, he encourages all to try to spare a few hours to learn, and reminds us that "when it comes to saving lives, every second counts, and any CPR is better than no CPR."

\section{Reference}

1. Fan KL, Leung LP, Siu YC. Out-of-hospital cardiac arrest in Hong Kong: a territory-wide study. Hong Kong Med J 2017;23:48-53. 